\title{
Completeness in the Swedish Fracture Register and the Swedish National Patient Register: An Assessment of Humeral Fracture Registrations
}

\author{
Carl Bergdahl (iD) ${ }^{1,2} *$ \\ Filip Nilsson ${ }^{2, *}$ \\ David Wennergren ${ }^{1,2}$ \\ Carl Ekholm ${ }^{1,2}$ \\ Michael Möller (iD) 1,2 \\ 'Department of Orthopaedics, Institute \\ of Clinical Sciences, Sahlgrenska \\ Academy, University of Gothenburg, \\ Gothenburg, Sweden; ${ }^{2}$ Department of \\ Orthopaedics, Sahlgrenska University \\ Hospital, Gothenburg/Mölndal, Sweden \\ *These authors contributed equally to \\ this work
}

\section{Video abstract}

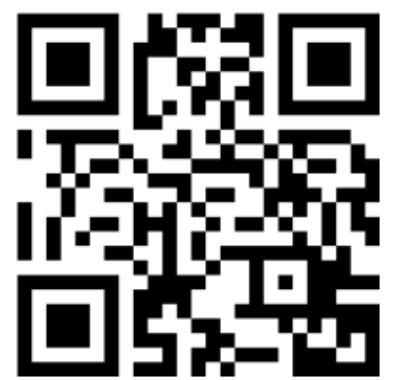

Point your SmartPhone at the code above. If you have a $Q R$ code reader the video abstract will appear. Or use: https://youtu.be/ehOmBFzrWBk

Correspondence: Carl Bergdahl Department of Orthopaedics, Sahlgrenska University Hospital, Göteborg, SE-4I 3 45, Sweden

Tel +46 31 3430888

Fax +46 31 278624

Email carl.bergdahl@vgregion.se
Purpose: Register-based clinical research is important. However, it is essential that the collected data are reliable for the registers to be a valuable source of information. This study evaluated the quality of humeral fracture data in the Swedish Fracture Register (SFR) and in the Swedish National Patient Register (NPR). Furthermore, a model for improved case ascertainment was developed for future validation processes.

Materials and Methods: Data were obtained from the NPR and SFR for all individuals aged $\geq 16$ years with an acute humeral fracture ICD-code treated at Sahlgrenska University Hospital. The true number of humeral fractures ("gold standard") was determined by crosslinkage between the two registers and a medical charts review. The completeness of registrations in each register was measured as the proportion of registrations compared with the gold standard, and accuracy was measured as positive predictive values (PPV).

Results: The NPR demonstrated a high level of completeness $(97 \%)$ and lower accuracy (PPV 70\%) for acute humeral fractures, whereas the SFR had slightly lower completeness $(88 \%)$ but perfect accuracy (PPV 100\%). The most common systematic error was the registration of re-admissions as acute fractures in the NPR ( $84 \%$ of all erroneous registrations). With this knowledge, an adjustment model for NPR data was constructed to increase the accuracy of fracture registrations (PPV 92\%) without excluding valid registrations.

Conclusion: Data from the NPR tend to overestimate the true number of fractures, and proper case selection is needed in order for the data to function as a solid basis for epidemiological research and healthcare planning. In contrast, the SFR constitutes a complete, accurate and efficient source of information.

Keywords: epidemiology, humeral fracture, registers, validation, completeness

\section{Introduction}

Observational register-based studies are able to address clinical issues that cannot easily be resolved by prospective randomized, controlled trials. ${ }^{1}$ Sweden, along with the other Nordic countries, has a long tradition of register-based clinical research. $^{2}$ The Swedish Board of Health and Welfare administers several nationwide population-based databases, such as the National Patient Register (NPR). ${ }^{3}$ The NPR is an administrative database which collects data on all diagnoses and surgical procedures in in-patient and out-patient specialist care. Alongside the NPR, the medical profession has developed more than 100 disease-specific national quality registers (NQRs), which have contributed vital knowledge to improve health care. ${ }^{2}$ The world's only NQR for fractures, the Swedish Fracture Register (SFR), has 
more than 500,000 fractures registered and is used continuously to analyze trends in treatment, adherence to clinical guidelines and treatment outcome. ${ }^{4-6}$ In recent years, administrative databases of electronic health records and professional-run quality registers have gained increasing popularity among clinical epidemiologists and serve as important tools in surveillance of diseases and injuries. ${ }^{7}$

The continuous assessment of data quality is important for registers to be effective and useful. Different areas, including accuracy, coverage and completeness, need to be validated. Several methods have been used to evaluate completeness in the NQRs. The most common is crosslinkage with another national register. $^{2}$ This method requires a valid reference, a "gold standard", with which the quality register of interest should be compared. Almost half the Swedish NQRs have used the NPR as a reference. ${ }^{8}$ However, administrative databases such as the NPR may be subject to diagnostic and coding errors. ${ }^{9}$ An imperfect "gold standard" generates a faulty validation. Only a few previous studies have evaluated the completeness of the NPR, all with conflicting results with regard to the total number of patients. ${ }^{9-12}$ No previous study has examined the completeness of the Swedish NPR for fractures, nor has the completeness of the SFR been analyzed in detail.

The aim of the present study was to evaluate the completeness and accuracy of humeral fracture registrations in the SFR and in the NPR regarding fractures treated at Sahlgrenska University Hospital (SUH). Furthermore, the study aimed to identify systematic errors in the registers to suggest ways to increase future validity.

\section{Materials and Methods Study Design and Setting}

The study was designed as a regional prevalence study using data from two independent registers, the NPR and the SFR. The NPR automatically collects longitudinal data and reached nationwide coverage for in-patient admissions in 1987 and for out-patient specialist visits in 2001. ${ }^{3}$ The NPR is administered by the Swedish Board of Health and Welfare. Data are continuously delivered from patientadministrative systems and medical records for in-patient care in hospitals and out-patient departments in hospitals. It is mandatory by law (SFS 1998:543 6§) for all healthcare providers in Sweden to submit data to the NPR. The information delivered to the NPR includes personal identity number (PIN), gender, name of hospital/out-patient department, admission and discharge dates, as well as diagnostic coding according to the Swedish version of the international classification of disease (ICD)-10 system. ${ }^{9}$ Regarding fractures, neither the time of injury nor the laterality of the injured body part is recorded. As a result, the NPR is unable to distinguish a readmission due to causes related to a previous fracture from an admission due to a new fracture, if an acute fracture code is used repeatedly.

The SFR is a web-based NQR created by orthopedic surgeons and data entry is performed by the attending physician. ${ }^{4}$ Detailed data on patient characteristics, date and mechanism of injury, fracture type, treatment modality, level of training of the treating physician and patientreported outcome measures (PROMs) are collected. Data are entered sequentially, meaning that altered treatments, reoperations or later treatments by another healthcare provider are connected to the initial fracture registration. Fractures sustained abroad and fractures in persons without a Swedish PIN are not included. Participation in the SFR is voluntary and it is not necessary for the healthcare provider to register data in the register. The coverage of the SFR has rapidly increased in recent years and in 2021, full national coverage was reached. The creation, implementation, validation and the registration process of the SFR have previously been described in detail. ${ }^{13-15}$

\section{Methods}

One quantitative method of assessing completeness is independent case ascertainment, which means that independent data sources are compared with each other in order to find true cases. ${ }^{16,17}$ While the NPR uses several sources for case notification (including data from public and private caregivers), the SFR is an independent source that is not used for case notification by the NPR. As a result, data can be compared between these registers in order to find ascertained cases and additional cases not primarily registered in the respective register.

In the present study, data were extracted from the NPR and the SFR on all individuals aged $\geq 16$ years, with an acute humeral fracture diagnostic code (ICD $10 \mathrm{~S} 42.2$ / S42.3/S42.4), treated at SUH between 1 January 2011 and 31 December 2012 (Figure 1). By using Swedish personal identification numbers (PIN), the cross-linkage of individuals was performed in the NPR and the SFR. An event (fracture) recorded in both registers was considered a valid fracture registration (matching registration). A fracture only recorded in one register was regarded as a mismatching registration. In patients with mismatching registrations, the medical records were reviewed and reasons for the 


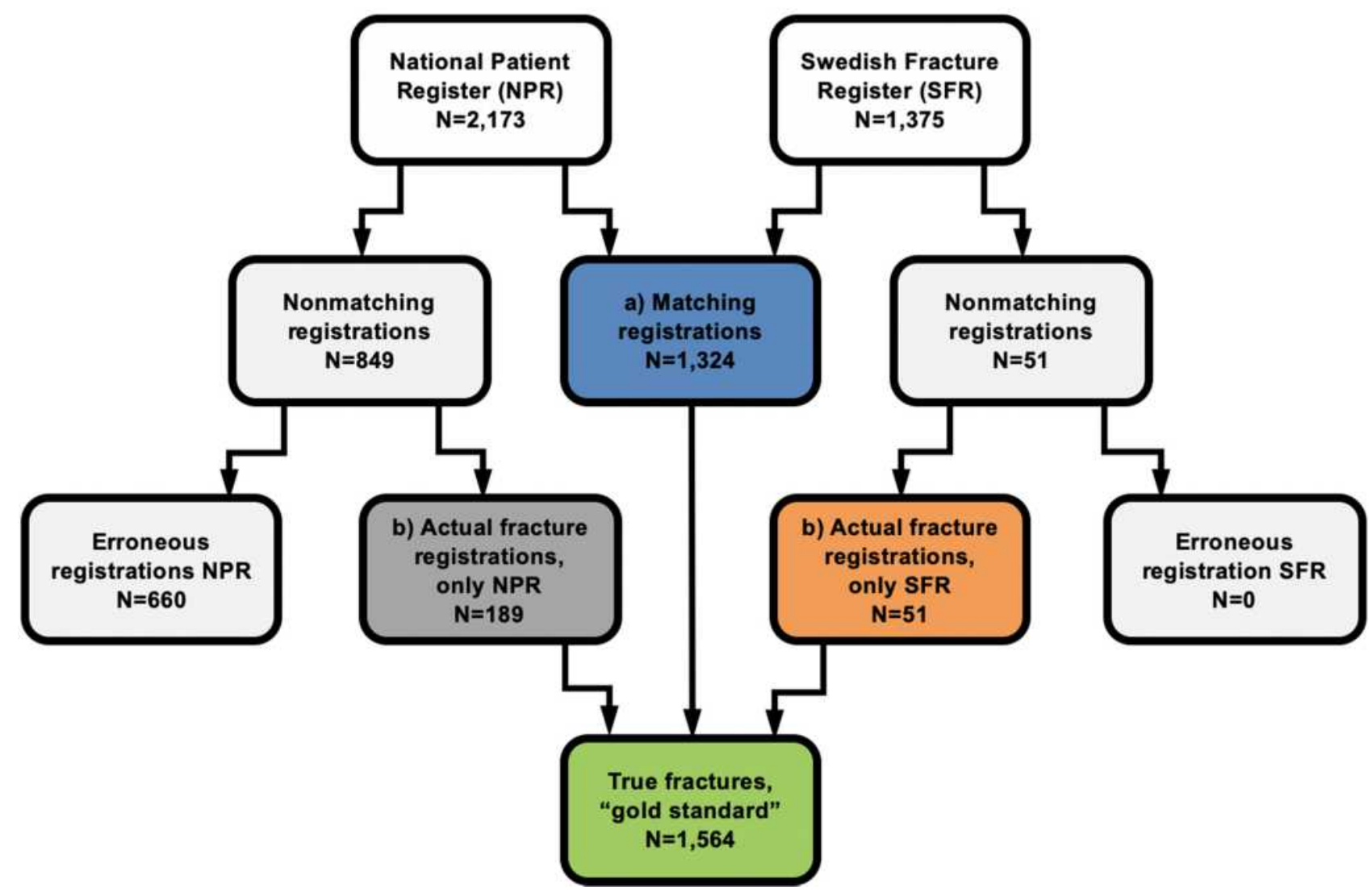

Figure I Flowchart of the study design and the assessment of the "true" number of acute humeral fractures at Sahlgrenska University Hospital in 20I I-20I2. The "true" number of fractures was defined by (a) all the fractures registered in both registers and (b) all the unique fractures registered in either register and verified by the medical records.

missing registration were searched for. A first time visit for a humeral fracture primarily treated at SUH during the study period was referred to as an "actual fracture", whilst all other reasons for the registration (ie re-admissions and non-humeral fractures registered as acute humeral fractures) were referred to as "erroneous registrations" (Table 1). The "true" number of humeral fractures during the study period was defined by (a) all fractures registered in both registers and (b) all unique fractures registered in either register and verified by the medical records. This "gold standard" was then used to assess completeness in both the NPR and the SFR.

\section{Statistics}

Completeness was calculated for both the SFR and the NPR as the total number of registrations in respective register divided by the "true" number of cases. To quantify accuracy, the positive predictive values (PPV) of the two registers were calculated. The PPV was calculated as the proportion of patients registered as having an acute humeral fracture who truly had an acute humeral fracture with a first-time visit for that fracture at SUH in 2011-2012. Completeness was assessed descriptively and the PPV was calculated with $95 \%$ confidence intervals (CI) according to normal approximation.

\section{Adjustment of NQR Data}

Nonmatching registrations were analyzed to identify systematic errors. To further sharpen accuracy regarding acute humeral fracture registration in the NPR, an algorithm was designed to exclude as many nonmatching registrations as possible in the NPR data, without excluding valid registrations of humeral fractures. The algorithm was then applied to data from 2016-2018 from other parts of Sweden (all counties attached to the SFR at least one year prior to 2016). By 2015 , approximately $40 \%$ of the departments treating orthopedic trauma in the country participated in the SFR.

The study was approved by the Central Ethical Review Board, Gothenburg (Ref no. 1018-13) and all data accessed complied with relevant data protection and privacy regulations. All patients were informed of the registration in the 
Table I Reasons for Registration in the National Patient Register

\begin{tabular}{|c|c|c|c|c|c|}
\hline & & & Number & $\begin{array}{l}\% \text { of All Registrations } \\
\text { (n. } 2173 \text { ) }\end{array}$ & $\begin{array}{l}\% \text { of Adjusted } \\
\text { Registrations* (n. 1648) }\end{array}$ \\
\hline \multicolumn{3}{|c|}{ Humeral fracture registration, actual fracture } & 1513 & 69.6 & 91.8 \\
\hline \multirow[t]{5}{*}{ Re-admission } & \multicolumn{2}{|c|}{ Re-registration at SUH during study period } & 317 & 14.6 & Excluded \\
\hline & $\begin{array}{l}\text { Humeral fracture prior to } \\
\text { study period }\end{array}$ & $\begin{array}{l}\leq 2 \text { years prior to re- } \\
\text { admission }\end{array}$ & 186 & 8.6 & Excluded \\
\hline & & $\begin{array}{l}\geq 2 \text { years prior to re- } \\
\text { admission }\end{array}$ & 16 & 0.7 & 1.0 \\
\hline & \multicolumn{2}{|c|}{$\begin{array}{l}\text { Humeral fracture primarily treated at another } \\
\text { Swedish orthopedic department }\end{array}$} & 22 & 1.0 & Excluded \\
\hline & \multicolumn{2}{|c|}{$\begin{array}{l}\text { Humeral fracture sustained and primarily treated } \\
\text { abroad }\end{array}$} & 11 & 0.5 & 0.7 \\
\hline \multicolumn{2}{|c|}{ Non-humeral fracture registration } & & 108 & 5.0 & 6.6 \\
\hline \multicolumn{2}{|l|}{ Total } & & 2173 & & \\
\hline
\end{tabular}

Note: *Adjustment algorithm used on NPR data for routine completeness calculation in the Swedish Fracture register. Abbreviation: SUH, Sahlgrenska University Hospital.

Swedish Fracture Register and that they had the right to decline registration. According to Swedish legislation (SFS 1998:543 6§), national quality registers do not require signed consent from the individual registered patients.

\section{Results}

During the study period, 1876 patients with 2197 acute humeral fractures were reported to the NPR from SUH and 1375 patients with 1375 acute humeral fractures were registered in the SFR from SUH. Twenty-four patients without a Swedish PIN were excluded from the NPR data, leaving 2173 registrations in the NPR eligible for analysis (Figure 1). There were 1324 matching registrations (true cases). A total of 900 nonmatching registrations were identified, of which 51 were in the SFR and 849 in the NPR. The 51 nonmatching registrations in the SFR were all actual humeral fractures missing in the NPR. Of the 849 nonmatching registrations present in the NPR, 189 were actual fractures that had not been registered in the SFR. As a result, the estimated number of true humeral fractures treated at SUH during the study period was 1564 .

Of the 2173 registrations in the NPR, 1513 (70\%) were actual humeral fractures treated at SUH in 2011-2012 (Table 1). The remaining 30\% $(\mathrm{n}=660)$ were erroneous registrations (ie registrations of re-admissions or nonhumeral fracture registrations). The majority of erroneous registrations were related to re-admissions for a previously registered humeral fracture $(\mathrm{n}=552 ; 84 \%)$, but 108 were registrations of other medical conditions (fractures in other parts of the body; $n=58$, other humeral injuries but no fracture; $n=33$, and other various conditions; $n=17$ ). Of the re-admissions, more than half $(\mathrm{n}=317 ; 57 \%)$ were additional registrations for a humeral fracture already registered during the study period and the remaining registrations $(\mathrm{n}=235 ; 43 \%)$ were re-admissions for an acute humeral fracture either sustained prior to the study period or primarily treated elsewhere. There were no patients with bilateral fractures or two different humeral fractures in the same humeral segment.

The NPR had a completeness of $97 \%$ and a positive predictive value (PPV) of 70\% (95\% CI: 68-72) for acute humeral fractures (Tables 2 and 3). When all the registrations from the NPR were used as a reference for completeness calculation, the SFR had an apparent completeness of $62 \%$. However, when erroneous registrations were excluded from the NPR data and true fractures were used as a reference, the actual completeness in the SFR was $88 \%$. The PPV in the SFR for acute humeral fractures was 100\% (95\% CI: 100-100) (Tables 2 and 3).

Information on erroneous registrations in the NPR is shown in Table 1. Based on these findings, an adjustment algorithm for NPR data was constructed accordingly; if all the individuals with an acute humeral fracture code (ICD10 S42.2-4) in the NPR that had been registered with the same fracture code within two previous years were excluded, the accuracy for actual acute humeral fractures 
Table 2 Calculated Completeness with Different Reference Data from the National Patient Register (NPR)

\begin{tabular}{|c|c|c|c|c|c|}
\hline & $\begin{array}{l}\text { Reference Data from the } \\
\text { NPR }\end{array}$ & $\begin{array}{l}\text { Number of } \\
\text { Registrations }\end{array}$ & $\begin{array}{l}\text { True Fractures } \\
\text { Missing }\end{array}$ & $\begin{array}{l}\text { Formula for } \\
\text { Completeness }\end{array}$ & $\begin{array}{c}\text { Completeness } \\
(\%)\end{array}$ \\
\hline \multirow[t]{3}{*}{ NPR } & All registrations & 2173 & 51 & $2173 /(1324+849+51)$ & 97.7 \\
\hline & $\begin{array}{l}\text { True number of humeral } \\
\text { fractures }\end{array}$ & 1513 & 51 & $1513 /(1324+|89+5|)$ & 96.7 \\
\hline & $\begin{array}{l}\text { Adjusted registrations in the } \\
\text { NPR* }^{*}\end{array}$ & 1648 & 51 & $1648 /(1324+324+51)$ & 97.0 \\
\hline \multirow[t]{3}{*}{ SFR } & All registrations & 1375 & 189 & $\mid 375 /(|324+5|+849)$ & 61.8 \\
\hline & $\begin{array}{l}\text { True number of humeral } \\
\text { fractures }\end{array}$ & 1375 & 189 & $\mid 375 /(|324+5|+\mid 89)$ & 87.9 \\
\hline & $\begin{array}{l}\text { Adjusted registrations in the } \\
\text { NPR* }\end{array}$ & 1375 & 189 & $\mid 375 /(|324+5|+324)$ & 80.9 \\
\hline
\end{tabular}

Note: *Adjustment algorithm used on NPR data for routine completeness calculations in the SFR.

Abbreviation: SFR, Swedish Fracture Register.

Table 3 Positive Predictive Value and Relationship to the True Number of Fractures (N. I564) with Different Reference Data in the National Patient Register (NPR)

\begin{tabular}{|c|c|c|c|c|c|c|c|}
\hline & $\begin{array}{l}\text { Reference } \\
\text { Data from } \\
\text { the NPR }\end{array}$ & $\begin{array}{l}\text { Number of } \\
\text { Registrations }\end{array}$ & $\begin{array}{l}\text { Number of } \\
\text { Actual } \\
\text { Fractures }\end{array}$ & $\begin{array}{l}\text { Erroneous } \\
\text { Registrations }\end{array}$ & $\begin{array}{l}\text { Positive } \\
\text { Predictive } \\
\text { Value (PPV) \% }\end{array}$ & $\begin{array}{l}\text { Confidence } \\
\text { Interval (95\%) } \\
\text { of PPV }\end{array}$ & $\begin{array}{l}\text { Relationship to the } \\
\text { True Number of } \\
\text { Fractures (\%) }\end{array}$ \\
\hline \multirow[t]{4}{*}{ NPR } & $\begin{array}{l}\text { All } \\
\text { registrations }\end{array}$ & 2173 & 1513 & 660 & 69.6 & $67.7-71.6$ & 138.9 \\
\hline & $\begin{array}{l}\text { True number } \\
\text { humeral } \\
\text { fractures }\end{array}$ & 1513 & 1513 & 0 & 100 & $100-100$ & 96.7 \\
\hline & $\begin{array}{l}\text { Number of } \\
\text { patients } \\
\text { (unique PINs) }\end{array}$ & 1852 & 1513 & 339 & 81.7 & $79.9-83.5$ & 118.4 \\
\hline & $\begin{array}{l}\text { Adjusted } \\
\text { registrations in } \\
\text { the NPR* }\end{array}$ & 1648 & 1513 & 135 & 91.8 & $90.5-93.1$ & 105.4 \\
\hline SFR & $\begin{array}{l}\text { All } \\
\text { registrations }\end{array}$ & 1375 & 1375 & 0 & 100 & $100-100$ & 87.9 \\
\hline
\end{tabular}

Note: *Adjustment algorithm used on NPR data for routine completeness calculations in the Swedish Fracture register.

Abbreviation: PIN, personal identification number.

in the NPR improved. With this modified NPR data, the PPV in the NPR increased to $92 \%$ (95\% CI: 90-93) without the loss of actual acute fracture registrations (Table 3 ).

When NPR data extracted via the adjustment algorithm were used as reference data ("gold standard"), the completeness for humeral fractures in the SFR in 2016-2018 was calculated to be between $75-90 \%$ in different counties (Figure 2).

\section{Discussion}

This study demonstrates that the NPR has a high level of completeness for actual acute humeral fractures, 97\%. However, a large proportion of registrations in the NPR were due to re-admissions or non-humeral fractures, and the PPV was as low as $70 \%$. This finding gives valuable information on how to interpret data from the NPR and avoid bias in epidemiological studies. The SFR at 


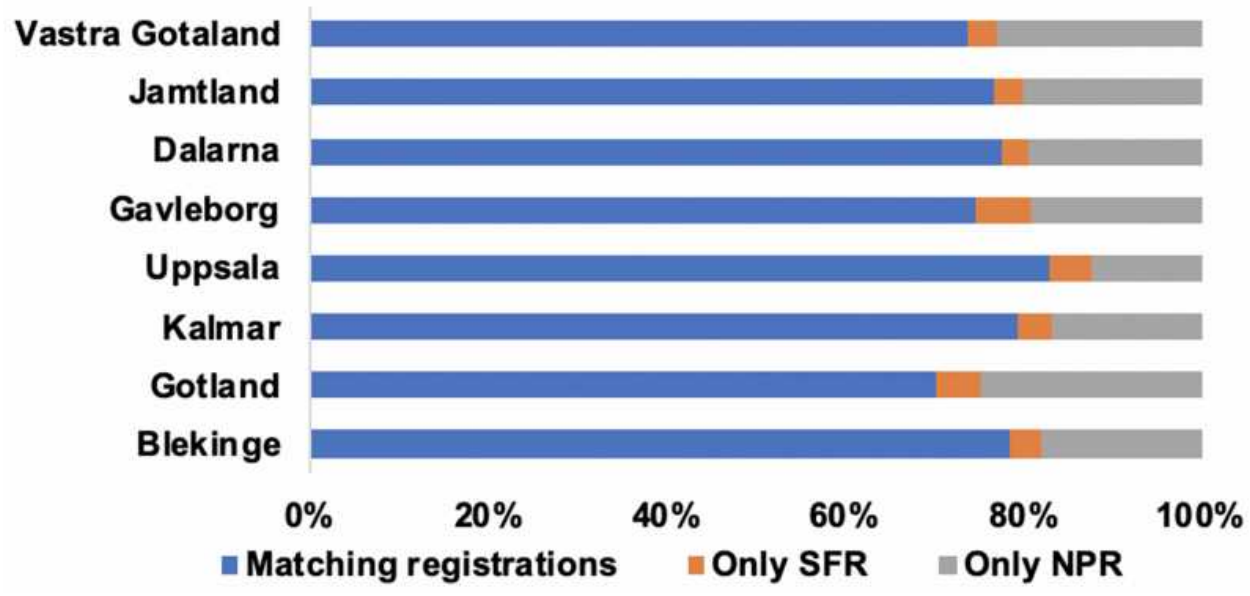

Figure 2 Calculation of completeness in the SFR (Swedish Fracture Register; attached counties) and NPR (National Patient Register) in 2016-20I8 according to the adjustment algorithm.

Sahlgrenska University Hospital showed a lower completeness level than the NPR (88\%) but a perfect PPV (100\%) for acute humeral fractures. This demonstrates that it is possible to achieve valid registrations in a NQR based on voluntary means.

A high degree of validity is of significant importance whenever register-based, observational data are used for research purposes or healthcare planning. ${ }^{1,9}$ In the Swedish NPR, the PPV has been reported to be between 85 and $95 \%$ and the completeness between 50 and $98 \%$ for various clinical conditions. ${ }^{9,12,18-20}$ Similar rates have been reported from disease-specific administrative databases in other parts of the world, however validation data regarding fracture registrations from outside of the Nordic region is sparse. ${ }^{21-24}$ The Nordic countries have a long tradition of register-based research and many validation studies originate from these countries. The completeness of $97 \%$ for acute humeral fractures in the NPR reported in this study is comparable with hip-fracture data in the NPRs of other Nordic countries. Lofthus reported a completeness rate of $89 \%$ for hip-fracture registrations in the Norwegian NPR from four centers in Oslo, while Emaus reported a $100 \%$ completeness rate from northern Norway, when compared with medical records. ${ }^{11,25}$ In Finland, Sund reported a completeness rate for hipfracture registrations of $97 \%$ in their NPR compared with audited data from a single center. ${ }^{26}$ To the best of our knowledge, no previous validation study of non-hip fractures has been performed on a Nordic NPR.

Using the estimated number of "true" humeral fractures in the current study, $3.3 \%$ of these fractures were missing in the NPR. In spite of this, the NPR reported 39\% more humeral fractures than the "true" number. One reason for this overestimation of cases is the lack of injury dates in the NPR. Re-admissions and follow-up visits for one fracture may generate several acute fracture codes in the medical charts and thereby multiple registrations in the NPR. ${ }^{27}$ A Norwegian study indicated that the Norwegian NPR overestimated the total number of hip fractures by $19 \%$ due to the inclusion of re-admissions for the same hip fracture. ${ }^{11}$ This phenomenon probably applies to other medical conditions, as approximately $30 \%$ of patients with a stroke in the NPR turned out to have had an earlier stroke when medical charts were reviewed. ${ }^{9}$

Of the humeral fractures registered in the NPR, only $70 \%$ were registrations of an actual acute humeral fracture. One quarter $(25 \%)$ of all registrations comprised readmissions or follow-up visits for a previous fracture. Pure diagnostic coding errors were less common, but still $5.0 \%$ of the humeral fracture registrations in the NPR were unrelated to a humeral fracture diagnosis. This aligns with the registration of other medical conditions in the NPR (dementia $10 \%$ and stroke 6\%). ${ }^{12,18}$ In comparison, the registrations in the SFR were all acute and unique humeral fractures. This demonstrates a high level of accuracy in the registrations in the SFR, probably due to the active registration process by orthopedic surgeons. Together with a completeness of $88 \%$ for acute humeral fractures, it indicates that data from the SFR collected at SUH are valid for epidemiologic studies. ${ }^{5,28}$

According to the National Board of Health and Welfare in Sweden, as many as 39 NQRs regularly use the NPR as a reference when assessing completeness. ${ }^{8}$ Completeness rates for the NQRs are reported to be between 6-97\% with 
this method of validation. In the current study, an apparent completeness of $62 \%$ for the SFR increased to $88 \%$ when the NPR was corrected for aberrant data. This highlights the necessity for all NQRs to validate the quality of their reference data, ie the NPR, in order to present trustworthy completeness rates. The validation of the reference data (ie the NPR) in the current study was conducted by independent case ascertainment enabled by PINs and medical records reviewing for non-matching registrations. This method is well established for validation studies but less useful for routine completeness calculations in NQRs, since it is time consuming and requires the handling of PINs. ${ }^{16,17}$ Routine transfer of information between registers is not allowed by Swedish legislation and certain rules apply to identifiable data (through the PINs, for instance) for integrity protection purposes. For this reason, the extraction and handling of PINs always require separate ethical approval. ${ }^{2,29}$

A surprisingly large discrepancy between the data reported to the NPR and the medical records indicates that an adjustment algorithm for humeral fracture NPR data could be warranted. In particular, if routine completeness calculations of the SFR used the NPR as a reference, such an adjustment algorithm would significantly increase the quality of the validation process. ${ }^{18,27}$ Similar algorithms for enhancing the case selection in the NPR have previously been constructed for the monitoring of stroke and myocardial infarction. ${ }^{18,30}$ The constructed adjustment algorithm is simple and will hopefully be useful in future validation work. When applying the constructed adjustment algorithm to the NPR data in this study, all the reoccurring registrations $(n=317 / 317 ; 100 \%)$, the majority of humeral fractures sustained prior to the study period $(\mathrm{n}=186 / 202 ; 92.1 \%)$ and all humeral fractures primarily treated in other departments in Sweden $(n=22 / 22 ; 100 \%)$ were correctly excluded. However, erroneous non-humeral fracture registrations $(n=108)$ and fractures sustained and primarily treated abroad $(\mathrm{n}=11)$ were not excluded. Unfortunately, the algorithm also excluded new humeral fractures (same humeral location, ie ICD10 S42.2-4) sustained within two years of the first fracture and all contralateral fractures, since laterality is not registered in the NPR. However, this appears to be uncommon for humeral fractures, since no re-occurring or bilateral fracture was found in this cohort. ${ }^{5}$ When the adjustment algorithm was used on the NPR data, the PPV increased from $70 \%$ to $92 \%$, indicating that such refined NPR data could be valuable in future SFR completeness calculations. There is reason to believe that the adjustment algorithm constructed in this study is warranted for NPR data in all parts of Sweden, since no substantial difference in the reporting of diagnoses have been demonstrated between different care givers obliged to report to the NPR. ${ }^{9}$ However, the adjustment algorithm needs further validation for different hospitals and counties in Sweden.

When using adjusted NPR data as a reference, the completeness for humeral fracture registration in the SFR was between $75-90 \%$ for various counties. This is in agreement with the reported completeness rates of the diagnose-specific hip fracture registers in the Nordic countries, but lower than the Swedish hip and knee arthroplasty registers (completeness rate $98 \%$ and $97 \%$ respectively, for primary procedures in the arthroplasty registers). ${ }^{31-34}$ Still, the completeness in the SFR is surprisingly high considering the different register set-ups; the arthroplasty registers have personnel employed for registration, as well as motivated and only surgically treated patients, and the SFR where data are collected and filed by the attending orthopedic physician. Registration in the SFR is noncompulsory and often performed in an acute setting at the accident and emergency department, without additional time reserved for the procedure. Despite these inherent difficulties, it appears to be possible to obtain high completeness rates for fracture registration in the SFR. In fact, the true completeness in the SFR might be even higher than the numbers presented in this study, since the reference data of the NPR still overestimates the number of acute humeral fractures in this material.

\section{Limitations}

One limitation with regard to generalizability is the confinement to a single center. However, this enabled a thorough medical chart review. A possible source of error are fractures that were not registered in either the NPR or the SFR. These cases would not be ascertained by the methodology used in this study. However, since the SFR and NPR demonstrated a high degree of matching registrations, this scenario seems unlikely according to a capture-recapture methodology. ${ }^{35,36}$

\section{Conclusion}

The first validation study of the NPR and the SFR regarding the completeness and accuracy of humeral fracture registrations indicates a high level of completeness for humeral fractures in the NPR, but NPR data tend to grossly overestimate the number of fractures. For this reason, unadjusted 
NPR data appear to be unsuitable for epidemiologic studies of fractures or as reference data in completeness calculations. On the other hand, data from the SFR demonstrated both acceptable completeness and perfect accuracy. This study illustrates that monitoring case ascertainment in new registers such as the SFR, as well as in established data sources such as the NPR, is valuable.

\section{Data Sharing Statement}

The datasets used and analyzed during the current study are available from the corresponding author in response to a reasonable request.

\section{Acknowledgments}

We wish to thank all the orthopedic surgeons at the affiliated department for entering detailed data on busy working days. This work has been performed in cooperation with the National Board of Health and Welfare. A special thanks to Henrik Passmark at the National Board of Health and Welfare, for providing us with data from the National Patient Register.

\section{Author Contributions}

FN and MM conceived the study idea and conducted the medical charts review. All authors contributed to the study design, the acquisition and analysis of the data. CB conducted the statistical calculations, created the tables and figures and wrote the first draft of the manuscript. All authors contributed took part in drafting the article or revising it critically for important intellectual content; agreed to submit to the current journal; gave final approval of the version to be published; and agree to be accountable for all aspects of the work.

\section{Disclosure}

The authors report no funding and no conflicts of interest in this work.

\section{References}

1. Anglemyer A, Horvath HT, Bero L. Healthcare outcomes assessed with observational study designs compared with those assessed in randomized trials. Cochrane Database Syst Rev. 2014;4:Mr000034.

2. Emilsson L, Lindahl B, Koster M, Lambe M, Ludvigsson JF. Review of 103 Swedish healthcare quality registries. J Intern Med. 2015;277 (1):94-136. doi:10.1111/joim.12303

3. The National Board of Health and Welfare (NBHW) (Socialstyrelsen). National Patient Register (NPR). Available from: https://www.social styrelsen.se/en/statistics-and-data/registers/register-information/thenational-patient-register/. Accessed January 10, 2021.
4. The Swedish Fracture Register (SFR) (Frakturregistret). Available from: https://sfr.registercentrum.se/. Accessed January 15, 2021.

5. Bergdahl C, Ekholm C, Wennergren D, Nilsson F, Moller M. Epidemiology and patho-anatomical pattern of 2011 humeral fractures: data from the Swedish fracture register. BMC Musculoskelet Disord. 2016;17:159. doi:10.1186/s12891-016-1009-8

6. Bergdahl C, Wennergren D, Ekelund J, Möller M. Mortality after a proximal humeral fracture. Bone Joint J. 2020;102-b (11):1484-1490. doi:10.1302/0301-620X.102B11.BJJ-2020-0627.R1

7. Casey JA, Schwartz BS, Stewart WF, Adler NE. Using electronic health records for population health research: a review of methods and applications. Annu Rev Public Health. 2016;37:61-81. doi:10.1146/annurev-publhealth-032315-021353

8. The National Board of Health and Welfare (NBHW) (Socialstyrelsen). Completeness (Tackningsgrad) 2019. Available from: https://www. socialstyrelsen.se/globalassets/sharepoint-dokument/artikelkatalog/ ovrigt/2019-12-6489.pdf. Accessed January 10, 2021.

9. Ludvigsson JF, Andersson E, Ekbom A, et al. External review and validation of the Swedish national inpatient register. BMC Public Health. 2011;11:450. doi:10.1186/1471-2458-11-450

10. Benjaminsen E, Myhr KM, Grytten N, Alstadhaug KB. Validation of the multiple sclerosis diagnosis in the Norwegian patient registry. Brain Behav. 2019;9(11):e01422. doi:10.1002/brb3.1422

11. Lofthus CM, Cappelen I, Osnes EK, et al. Local and national electronic databases in Norway demonstrate a varying degree of validity. J Clin Epidemiol. 2005;58(3):280-285. doi:10.1016/j.jclinepi.2004.07.003

12. Rizzuto D, Feldman AL, Karlsson IK, Dahl Aslan AK, Gatz M, Pedersen NL. Detection of dementia cases in two swedish health registers: a Validation Study. $J$ Alzheimers Dis. 2018;61 (4):1301-1310. doi:10.3233/JAD-170572

13. Wennergren D, Ekholm C, Sandelin A, Möller M. The Swedish fracture register: 103,000 fractures registered. BMC Musculoskelet Disord. 2015;16(1):338. doi:10.1186/s12891-015-0795-8

14. Wennergren D, Möller M. Implementation of the Swedish fracture register. Der Unfallchirurg. 2018;121(12):949-955. doi:10.1007/ s00113-018-0538-z

15. Wennergren D, Stjernstrom S, Moller M, Sundfeldt M, Ekholm C. Validity of humerus fracture classification in the Swedish fracture register. BMC Musculoskelet Disord. 2017;18(1):251. doi:10.1186/ s12891-017-1612-3

16. Goldberg J, Gelfand HM, Levy PS. Registry evaluation methods: a review and case study. Epidemiol Rev. 1980;2:210-220. doi:10.1093/oxfordjournals.epirev.a036224

17. Appelros P, Terént A. Validation of the Swedish inpatient and cause-of-death registers in the context of stroke. Acta Neurol Scand. 2011;123(4):289-293. doi:10.1111/j.1600-0404.2010.01402.x

18. Köster M, Asplund K, Johansson Å, Stegmayr B. Refinement of Swedish administrative registers to monitor stroke events on the national level. Neuroepidemiology. 2013;40(4):240-246. doi:10.1159/000345953

19. Rück C, Larsson KJ, Lind K, et al. Validity and reliability of chronic tic disorder and obsessive-compulsive disorder diagnoses in the Swedish national patient register. BMJ Open. 2015;5(6):e007520. doi:10.1136/bmjopen-2014-007520

20. Arthursson AJ, Furnes O, Espehaug B, Havelin LI, Soreide JA. Validation of data in the Norwegian arthroplasty register and the Norwegian patient register: 5134 primary total hip arthroplasties and revisions operated at a single hospital between 1987 and 2003. Acta Orthop. 2005;76(6):823-828. doi:10.1080/17453670510045435

21. Burns EM, Rigby E, Mamidanna R, et al. Systematic review of discharge coding accuracy. J Public Health. 2012;34(1):138-148. doi:10.1093/pubmed/fdr054

22. Hudson M, Avina-Zubieta A, Lacaille D, Bernatsky S, Lix L, Jean S. The validity of administrative data to identify hip fractures is high-a systematic review. J Clin Epidemiol. 2013;66(3):278-285. doi:10.1016/j.jclinepi.2012.10.004 
23. Quach S, Blais C, Quan H. Administrative data have high variation in validity for recording heart failure. Can J Cardiol. 2010;26 (8):306-312. doi:10.1016/S0828-282X(10)70438-4

24. Tomotaki A, Kumamaru H, Hashimoto H, et al. Evaluating the quality of data from the Japanese National Clinical Database 2011 via a comparison with regional government report data and medical charts. Surg Today. 2019;49(1):65-71. doi:10.1007/s00595-0181700-5

25. Emaus N, Heiberg I, Ahmed LA, et al. Methodological challenges in hip fracture registration: the harstad injury registry. Int J Inj Contr Saf Promot. 2011;18(2):135-142. doi:10.1080/17457300.2010.540331

26. Sund R, Nurmi-Lüthje I, Lüthje P, Tanninen S, Narinen A, Keskimäki I. Comparing properties of audit data and routinely collected register data in case of performance assessment of hip fracture treatment in Finland. Methods Inf Med. 2007;46(5):558-566. doi:10.1160/ME0382

27. Gedeborg R, Engquist H, Berglund L, Michaelsson K. Identification of incident injuries in hospital discharge registers. Epidemiology. 2008;19(6):860-867. doi:10.1097/EDE.0b013e318181319e

28. Wennergren D, Bergdahl C, Ekelund J, Juto H, Sundfeldt M, Möller M. Epidemiology and incidence of tibia fractures in the Swedish fracture register. Injury. 2018;49(11):2068-2074. doi:10.1016/j.injury.2018.09.008

29. Ludvigsson JF, Otterblad-Olausson P, Pettersson BU, Ekbom A. The Swedish personal identity number: possibilities and pitfalls in healthcare and medical research. Eur J Epidemiol. 2009;24(11):659-667. doi:10.1007/s10654-009-9350-y

30. Madsen M, Davidsen M, Rasmussen S, Abildstrom SZ, Osler M. The validity of the diagnosis of acute myocardial infarction in routine statistics: a comparison of mortality and hospital discharge data with the Danish MONICA registry. J Clin Epidemiol. 2003;56 (2):124-130. doi:10.1016/S0895-4356(02)00591-7
31. Gjertsen JE, Engesaeter LB, Furnes O, et al. The Norwegian hip fracture register: experiences after the first 2 years and 15,576 reported operations. Acta Orthop. 2008;79(5):583-593. doi:10.1080/ 17453670810016588

32. Kärrholm JRC, Nauclér E, Vinblad J, Mohaddes M, Rolfson O. The Swedish hip arthroplasty register (Svenska höftprotesregistret). Annual Report 2018. Available from: https://registercentrum.blob. core.windows.net/shpr/r/Arsrapport_2018_Hoftprotes_ENG 26mars Final-rJepCXNsLI.pdf. Accessed January 12, 2021.

33. Meyer AC, Hedström M, Modig K. The Swedish hip fracture register and national patient register were valuable for research on hip fractures: comparison of two registers. $J$ Clin Epidemiol. 2020;125:91-99. doi:10.1016/j.jclinepi.2020.06.003

34. Robertsson OW-DA, Lidgren L, Sundberg M. The Swedish knee arthroplasty register (Svenska Knäprotesregistret). Annual Report 2019. Available from: https://www.myknee.se/pdf/SVK_2019_1.0_ Eng.pdf. Accessed January 12, 2021.

35. Chao A, Tsay PK, Lin SH, Shau WY, Chao DY. The applications of capture-recapture models to epidemiological data. Stat Med. 2001;20 (20):3123-3157. doi:10.1002/sim.996

36. Wittes JT, Colton T, Sidel VW. Capture-recapture methods for assessing the completeness of case ascertainment when using multiple information sources. J Chronic Dis. 1974;27(1):25-36. doi:10.1016/ 0021-9681(74)90005-8
Clinical Epidemiology

\section{Publish your work in this journal}

Clinical Epidemiology is an international, peer-reviewed, open access, online journal focusing on disease and drug epidemiology, identification of risk factors and screening procedures to develop optimal preventative initiatives and programs. Specific topics include: diagnosis, prognosis, treatment, screening, prevention, risk factor modification,

\section{Dovepress}

systematic reviews, risk \& safety of medical interventions, epidemiology \& biostatistical methods, and evaluation of guidelines, translational medicine, health policies \& economic evaluations. The manuscript management system is completely online and includes a very quick and fair peer-review system, which is all easy to use. 